\title{
Espaços Interditos e a Constituição das Identidades Travestis através da Prostituição no Sul do Brasil ${ }^{1}$
}

\author{
Interdicts Spaces and Constitution of Travestis Identities through Prostitution in \\ Southern Brazil
}

\author{
Marcio Jose Ornat ${ }^{2}$ \\ Universidade Estadual de Ponta Grossa \\ geogenero@gmail.com
}

\section{Resumo}

A presente discussão tem por objetivo evidenciar a relação entre espacialidades interditas e a constituição de elementos identitários travestis. Estas reflexões nasceram do resultado da realização de um conjunto de dezenove entrevistas no Sul do Brasil e três na Espanha com travestis que retiram seu sustento da atividade da prostituição. Este volume de falas produziu um conjunto de 1.009 evocações que se relacionaram as principais espacialidades vivenciadas pelas travestis. Abordamos nesta discussão as espacialidades referentes a casa, a escola e a vizinhança, a cidade e as casas noturnas, as pensões para travestis e as boates. A existência travesti é atravessada por espaços interditos e por espacialidades relacionadas direta ou indiretamente a atividade da prostituição. $\mathrm{O}$ paradoxo de suas existências relacionase a processos espaciais de exclusão e de acolhida, a partir de formas contraditórias e complementares. Assim, estes processos não se colocam como oposicionais, mas complementam-se compondo espacialidades travestis multidimensionais.

Palavras-chave: Espaços interditos; prostituição travesti; identidades.

\begin{abstract}
This discussion aims to evidence the relationship between interdicts spatialities and the constitution of identity elements travestis These ideas were born from the result of performing a set of nineteen interviews in southern Brazil and three interviews in Spain with travestis who live the activity of prostitution. This speaks produced a volume of 1.009 invocations that related the main spatiality experienced by travestis. We approach this discussion spatialities relating to home, school and neighborhood, city and nightclubs, pensions for travestis and nightclubs. The existence travesti is crossed by interdicts spaces and spatialities directly or indirectly related to activity of prostitution. The paradox of their existence is related to spatial processes of exclusion and welcome, from complementary and contradictory ways. Thus, these processes do not pose as oppositional, but complement each other forming multidimensional travestis spatialities.
\end{abstract}

Keywords: Interdicts spaces; travesti prostitution; identity. 


\section{Considerações Iniciais}

Esta discussão evidencia a relação entre espacialidades interditas e a constituição de elementos identitários travestis. Todas as reflexões nasceram do resultado da realização de um conjunto de dezenove entrevistas no Sul do Brasil e três na Espanha ${ }^{3}$, entre o período de maio de 2008 a dezembro de 2010, com travestis que retiram seu sustento da atividade da prostituição. Não trabalhamos nesta reflexão o termo travesti como sinônimo dos termos transgender ou transvestite, pois mesmo que reconheçamos a existência de um conjunto considerável de reflexões relacionadas aos dois últimos termos, como visto nas proposições relacionadas a Browne (2004) tratando da co-relação entre a rematerialização de locais e corpos sexuados, Browne, Nash e Hines (2010) tratando da fluidez do gênero e da sexualidade a partir da existência de corpos 'trans', questionando as convenções hegemônicas, Browne e Lim (2010) analisando as geografias das vidas 'trans', Doan (2007) explorando as conexões complexas entre pessoas transgender e a cidade, ou melhor, entre espaços queer e a cidade, Doan (2010) analisando as consequências do sistema binário de normas de gênero, tanto para aqueles que transgridem as normas, como para aqueles que vivem suas vidas através destas restrições, Hines (2010) explorando as conexões entre subjetividades 'trans' e espaços comunitários, Knopp (2004) pensando o transgender a partir de ontologias espaciais, deslugaridades e movimentos, Nash (2010) refletindo sobre o transgender a partir de suas geografias, corporeidades e experiências, e Rooke (2010) analisando a criação de espaços 'trans' a partir da juventude 'trans', da ciência e da arte, partimos da proposição de Silva (2009a), pois mesmo que a palavra 'travesti' tenha o significado de apropriação de alguns elementos do gênero oposto, encaminhado tanto a partir de fetiches ou irreverência social, este significado não se refere a travesti brasileira.

Corroborando com o afirmado pela autora, a partir do contato e convivência com travestis sul-brasileiras, para este grupo, o termo travesti refere-se a uma busca constante e integral da feminilidade, a partir do par vestimenta/maquiagem/adereços e comportamentos sociais. Mas, além disso, uma busca constante da transformação do corpo, a partir da utilização de hormônios e silicone, sem que isso se finalize em uma operação de trangenitalização. Desta forma, a palavra 'travesti' tem pouca correspondência à palavra transvestite, que é compreendida por D. Valentine (2007), como um correspondente do termo crossdresser. Segundo o autor, os dois termos relacionam-se a um disgnóstico psiquiátrico ${ }^{4}$ de pessoas que são heterossexuais, mas que constituem práticas eróticas a partir da utilização de roupas femininas.

Outro elemento refere-se ao fato de que, como tratado por Silva (2009a), o termo transgender, lido no Brasil como 'transgênero', refere-se ao transitar entre os papéis de gênero, e neste sentido, transgredindo a ordem hegemônica, todavia termo não reconhecido como uma identificação de grupo. Como visto pela autora, o próprio movimento político travesti brasileiro pensa o termo enquanto produto nacional, indicando que tanto a sociedade brasileira como a produção teórica anglófona não se apropriaram destas terminologias.

Uma discussão necessária refere-se à abordagem de Kulick (2008) em relação à travesti, a partir da prostituição, do sexo, gênero e cultura no Brasil. Segundo reflexões etnometodológicas do autor, na afirmação da subjetividade travesti, enquanto uma identidade brasileira, o sexo e o gênero não se colocam enquanto estados ontológicos, mas são o resultado de todas as práticas cotidianas. Para o autor, a travesti enquanto uma forma de transgenderismo, não seria uma ocorrência natural ou arbitrária, mas emergiria de especificidades espaciais e temporais.

O equivoco de Kulick (2008) assenta-se na limitação da prática sexual travesti apenas relacionada à passividade sexual. Como visto em suas palavras, "o lócus da diferença de gênero é o ato da penetração. Se a pessoa 'só' penetra, é homem. Se a pessoa é penetrada, é diferente de homem - e aí pode ser um 'viado' ou uma mulher" (KULICK, 2008, p. 236). Mesmo que a reflexão de Kulick seja importante, a partir da afirmação de que o grupo de travestis possuem especificidades próprias, falha quando simplifica generalizando todas as travestis brasileiras a este modelo binário 'penetrante - penetrada'.

Consideramos que a generalização da categoria transgender ou transvestite a várias possibilidades de questionamento da linearidade entre sexo, gênero, prática sexual e desejo relaciona-se a uma forma de 'estrabismo anglófono', como nomeado por Whitehand (2005). Segundo este autor, a pequena atenção direcionada pela produção anglófona a produção teórica de outras línguas é uma condição que existe de forma acentuada desde o pós II Guerra Mundial, registrado em publicações, condição esta de carácter mais político que intelectual. A partir da discussão sobre a hegemonia de revistas geográficas e sua indexação, Whitehand aponta que estas se colocam como internacionais apenas no mundo anglófono internacional. Além da fraca representação de reflexões não anglófonas, para o autor a maioria dos pesquisadores anglófonos não dominam outras línguas. Assim, outras discussões são desconhecidas, fato que 
ocorre, paradoxalmente, ao lado da nossa tomada de consciência, pela produção não anglófona, da necessidade de diálogo internacional.

Outro argumento apoia-se na própria proposta de Butler (2006), quando esta afirma que o 'eu' que existe encontra-se relacionado às normas, e dependendo delas, normas estas que são temporais e espaciais. Estas relações do 'eu' com as normas também buscam orientar-se de forma crítica e transformadora. Para ela, o 'eu' não pode ser reconhecido fora destas normas, mas pelo contrário, quando este 'eu' é incorporado pela norma, torna-se inteligível através desta. É equivocado atribuir à travesti uma única identidade, pois estas construções formam-se a partir de determinadas espacialidades e temporalidades, segundo imbricações entre gênero e sexualidades, identidades e espaço.

Portanto, o conjunto de falas ${ }^{5}$ que nasceu de pessoas que se auto-identificavam como travestis fora analisado segundo a constituição de redes semânticas, assim como proposto por Bardin (1977). Tratamos de pessoas que possuem práticas cotidianas não adequadas à heteronormatividade vigente, pois assim como Peres (2005) propõe, estas pessoas são homens no sentido fisiológico, relacionando-se com o mundo como mulheres. A partir destas vivências, nossa compreensão parte da prerrogativa de que o espaço é feito, segundo as práticas sociais incorporadas e como visto por Massey, Allen e Sarre (1999), segundo a produção social de um espaço vivenciado cotidianamente, resultado de versões particulares de performances relacionais.

Todas as intersecções de diferentes dimensões de categorias identitárias das travestis são co-constituídas através de relações entre espacialidades e temporalidades. Evidenciamos que as memórias espaciais que foram resgatadas pelas travestis através do processo de pesquisa são elementos que constituem identidades interseccionais enquanto grupo de travestis, sendo as memórias resgatadas elementos de afirmação grupal. Mesmo que não sejam idênticas a todas as travestis, os elementos que se colocam como comuns são elementos de identificação, através do cruzamento de experiências passadas, que são socializadas através dos territórios da prostituição travesti. Como proposto por Silva (2009b), os jogos de intertextualidades que produzem as espacialidades são também instituídos pela composição textoespacialidade da experiência travesti, denominada pela autora como a produção do espaço interdito, ou seja, formada por práticas discursivas descontínuas, que ora se cruzam, ora se ignoram ou se excluem, formando ora sim, ora não, interdições de vivências espaciais a estas pessoas, que através das relações cotidianas, são socializadas.
Após a análise de todas as falas fora detectado um conjunto de 1.009 evocações ${ }^{6}$ que se relacionaram as principais espacialidades vivenciadas pelas travestis em todas as fazes da vida, referentes a cidade, a casa, a pensão para travestis, a escola, outros países, a vizinhança, além dos maiores percentuais relacionados aos territórios intra-urbanos e ao território descontinuo da prostituição travesti.

Devido ao escopo da presente reflexão, abordamos as espacialidades relacionadas a casa, a escola e a vizinhança, a cidade e as casas noturnas, a pensão para travestis e as boates. Desta forma, em um primeiro momento tratamos sobre o binômio espacialidade e interseccionaldade, para em um segundo momento discutir as experiências socializadas a nós através do processo de pesquisa, referentes as existências espaciais paradoxais de exclusão e acolhida, segundo contradições e complementaridades, que compõe espacialidades travestis multidimensionais.

\section{Espacialidades, Interseccionalidades e Sujeito Travesti}

O espaço é objeto de um amplo debate dentro das ciências sociais, e como visto por Corrêa (1995) envolvendo geógrafos e não geógrafos. Como tratado pelo autor, o espaço fora visualizado em toda a história do pensamento geográfico como absoluto, relativo, concebido como planície isotrópica e representado a partir de matrizes e grafos, descrito tanto através de várias metáforas quanto reflexo e condição social, experienciado de várias formas, carregado em simbolismos e campo de lutas. Evidenciamos nesta reflexão a importância do espaço para o grupo objetivado, espacialidades estas que compõe sujeitos sociais, com suas trajetórias e vivências cotidianas.

Todas as espacialidades desenvolvidas pelo grupo de travestis ao longo de suas vidas são elementos de fundamental importância, pois são estas espacialidades que constrangem as posições dos sujeitos, compondo suas relações de força e orientando suas escolhas e formas de apreensão da vida cotidiana. Evidenciamos a co-relação entre espacialidades e elementos identitários de identificação, que foram resgatados pelas memórias das travestis. Estas criam tanto laços de afetividade de pertença grupal quanto à diferenciação no tocante a outros grupos sociais.

As espacialidades que são compostas e compõem as memórias das travestis são constituídas pelo paradoxo, formadas pela heteronormatividade e sua transgressão. As identidades são uma construção social, feitas a partir de várias temporalidades e espacialidades, e a partir da reiteração de conjuntos de 
normas que são anteriores aos sujeitos, como tratado por Butler (2003), posicionam pessoas ora no centro, ora na margem destas mesmas relações, a partir de fronteiras espaciais e sociais porosas.

Como analisado por Hall $\left(2003^{7}\right)$, a intensificação das discussões relacionadas ao conceito de identidade refere-se ao fato de que as velhas identidades que estavam por muito tempo estabilizadas deram lugar a um conjunto de identidades fragmentadas, visualizando um indivíduo não mais unitário. Segundo sua perspectiva, esta 'crise de identidades' refere-se a uma ampla dinâmica que desloca estruturas e processos que são centrais na sociedade moderna, desestruturando todos os quadros fixos de referência para todo o mundo social. Nesta perspectiva, viveríamos hoje a partir de configurações fragmentadas segundo existências compostas por várias identidades provisórias e variáveis.

Existe uma recusa em pensar as identidades a partir de possibilidades essencialistas, indicando estas como processos de identificações cambiantes e móveis, temporalmente e espacialmente. Isto demonstra que quando a identidade é pensada segundo uma perspectiva geográfica, ela coloca-se enquanto situada. Como analisado por Pratt (1999), ao invés de vermos identidades a partir de uma essência, construímos visões parciais sobre as identificações dos grupos sociais. A proposta da autora é pensar os limites entre identidades como fractais, limites estes estabelecidos de forma não estrutural ou regular.

Como visto por Hall (2003), desde o projeto do Iluminismo até hoje, haveria um processo de desestabilização das identidades. Por outro lado, como proposto por Pratt (1999), algumas identidades são mais móveis do que outras, pensando esta maior ou menor mobilidade de identidades tanto em termos espaciais quanto temporais, todas elas envolvendo processos de inclusão e exclusão.

Uma das direções profícuas para se pensar a relação entre identidades e espacialidades têm se alocado nas discussões referentes ao conceito de 'interseccionalidade', ferramenta esta utilizada para demonstrar a teorização não entre identidades, mas a conexão de dimensões entre distintas categorias identitárias, tais como raça, gênero, sexualidade e etc.

Segundo G. Valentine (2007), este conceito tem recebido relativamente pouca atenção dos geógrafos, mesmo que alguns trabalhos se coloquem na vanguarda deste sub-campo, como visto pela autora, nos trabalhos relacionados a Peake (1993) discutindo a relação entre os desafios da estrutura patriarcal no espaço urbano através da co-relação entre raça e sexualidade, Kobayashi e Peake (1994) analisando a interface entre raça e gênero na Geografia, Ruddick
(1996) refletindo sobre as diferenças nos espaços públicos a partir de sistemas de interlocução entre raça, classe social e gênero, e Pratt analisando primeiramente (1999) as geografias das identidades e diferenças a partir de fronteiras em seu fazer, e em seguida (2002) pensando as colaborações entre as fronteiras.

O feminismo surgiu nas discussões das ciências sociais a partir de sua relação com o próprio movimento feminista, como visto por Narvaz e Koller (1996). Estes movimentos sociais tinham por pauta, como tratados por G. Valeiintine (2007), as questões de desigualdade nas relações de poder de raça, patriarcado e classes sociais. No âmbito da ciência geográfica, as reflexões apontavam para a incapacidade de integração das mulheres como sujeitos identitários na investigação científica, como no exemplo da publicação de Monk e Hanson (1982) em seu célebre artigo intitulado 'On Not Excluding Half Human in Human Geography'.

Da mesma forma, no livro publicado pelo Women and Geography Study Group (1984), no qual introduzia as reflexões sobre Geografia e gênero à Geografia Feminista, as discussões apontavam para a demanda de se pensar, a partir deste caminho, o acesso à cidade, ao emprego e a infra-estrutura. Mesmo que nas décadas posteriores as pesquisas geográficas feministas tivessem adicionado uma gama crescente de temáticas, as interconexões entre diferentes dimensões de categorias identitárias foram relegadas a supervalorização de uma categoria em detrimento das demais nas relações de interseccionalidade.

Uma das contundentes críticas que foram o nascimento do conceito de interseccionalidade referese ao fato de que as reflexões relacionadas às interconexões de opressão se faziam a partir de discursos, como tratado por G. Valentine (2007), das experiências de mulheres, que possuíam facetas identitárias relacionadas à cor da pele - eram mulheres brancas e de classe média. Assim, devido aos recursos de capital cultural, as discussões feministas não eram originadas de grupos invisíveis, pois poucas pessoas que advinham de grupos sociais excluídos conseguiam entrar nas universidades. Se de um lado eram as feministas brancas que haviam aberto o caminho para as discussões relacionadas ao gênero, a participação das feministas negras mostrava-se pequena nas organizações de feministas brancas.

Esta mudança de posição conduziu as pesquisas ao descentramento de uma única posição identitária do sujeito investigado, abrindo caminho para uma pluralidade de feminismos. Entretanto, como afirmado por G. Valentine (2007), a primeira publicação relacionada às interconexões entre diferentes 
categorias identitárias de sujeito deve-se a discussão das sociólogas Andersen e Colins (1992), a partir do livro 'Race, Class and Gender: An Anthology'.

Nesta obra, as autoras reconhecem a impossibilidade de nas pesquisas sociais, se trabalhar com categorias identitárias em separado, como raça, classe, gênero e sexualidades. A impossibilidade se relaciona nesta discussão ao fato de que as desigualdades não podem ser explicadas a partir de um único quadro teórico ${ }^{8}$. Assim, fora desafiado o fato de que as pessoas negras tinham apenas uma raça, as mulheres brancas tinham um gênero, as mulheres negras experiencias de raça e gênero, ao passo que os homens brancos não eram marcados. Como visto pelas autoras, o conceito de interseccionalidade é creditado a Crenshaw (1994) em 'Mapping the Margins: Intersectionality, Identity Politics, and Violence Against Women of Color'.

Neste caminho, nos utilizamos para pensar a constituição de sujeitos travestis a partir da exploração das dimensões do 'eu' que se entrecruzam. O conceito principal construído por Crenshaw refere-se ao de interseccionalidade, relacionando-se a situação de interação entre vários caminhos de experiência do sujeito, formando várias dimensões de existência espacial. Isto aponta para o não privilégio de uma categoria identitária em detrimento das demais, pois quando olhado o grupo a partir de possibilidades interseccionais, elementos como gênero, sexualidades, grupo de renda, faixa etária, cor da pele, etc, não podem ser visto como instâncias identitárias do sujeito em separado.

Esta possibilidade não aponta para uma visão totalizante das identidades, como também não evidencia que a formação de sujeitos travestis só possa ser visto, como defendido por Crenshaw (1994), a partir de quadros de gênero e sexualidade. Nosso olhar se orienta para uma organização calidoscópica da formação destes sujeitos, olhar este não final. A intersecção evidenciada, através das falas das travestis que são o grupo focal da presente discussão, relacionase aos encontros de elementos identitários relacionados ao gênero, sexualidades, cor da pele, faixa etária e grupo de renda, demonstrando que as identidades são construções sociais em um mundo construído.

Estas considerações revelam que as interseccionalidades formam experiências de vivências espaciais cotidianas. As reflexões de acesso ao emprego, a habitação e a possibilidade de sobrevivência econômica relacionam-se as estruturas de funcionamento de uma sociedade organizada a partir de grupos de renda, colocando-se como um importante elemento da definição da experiência das pessoas. Entretanto, é um equivoco afirmar que este é o principal elemento, pois existe o entrecruzamento de diversas experiências, não sendo as questões de classe social independentes das de gênero, sexualidades, cor da pele, faixa etária, etc.

A partir do exemplo construído por Crenshaw (1994) no tocante às mulheres de cor que sofrem violência, agora em outra direção fenomenal, em relação ao grupo das travestis que retiram seu sustento da atividade da prostituição no Sul do Brasil, os elementos identitários relacionados à cor da pele, gênero, classe social, faixa etária e sexualidade relacionam-se em conjunto. Além do fato do grupo relacionar-se a pessoas com baixo poder aquisitivo, o fenômeno da discriminação relacionado a este elemento identitário se reproduz através de seus comportamentos de gênero e sexualidade. A metáfora de Crenshaw refere-se a um entroncamento rodoviário, onde vários acidentes acontecem, mas que não são relatados. Se por um lado, a interseccionalidade é analisada, como visto em G. Valentine (2007), na forma como um indivíduo fica em uma encruzilhada, esta ferramenta consegue capturar que a diferença não se encontra nos espaços entre identidade, mas através das espacialidades.

Conduzindo as discussões por estes mesmos caminhos, as primeiras tentativas de se pensar a interconexão entre diferentes categorias identitárias baseava-se, segundo G. Valentine (2007), em uma busca de calcular os sistemas de opressão a partir da utilização de metáforas geométricas ou matemáticas, a partir da adição, multiplicação, localização e posição. As reflexões faziam-se sob o caminho de que os sistemas de opressão eram somados uns aos outros. Isso se refere ao exemplo de que uma mulher negra com deficiência seria mais oprimida do que uma mulher apenas negra. Entretanto, isso é rechaçado.

Estes mecanismos apontam para a questão de que, assim como relações sociais concretas e articuladas entre si, as específicas intersecções podem produzir efeitos distintos, através das espacialidades. Como visto, as categorias identitárias são circunstanciais, se negando, se anulando e se fortalecendo. O lastro desta afirmação refere-se à proposição de Butler (2003), onde cada indivíduo experimenta todas as facetas identitárias simultaneamente, pois "Se alguém 'é' uma mulher, certamente isto não é tudo o que esse alguém é (...) o gênero estabelece intersecções com modalidades raciais, classistas, étnicas, sexuais e regionais de identidade discursivamente construídas." (BUTLER, 2003, p. 20).

Assim, o caminho produtivo não é o entrecruzamento somatório de experiências de sujeitos, mas pensar as identidades como ações realizadas sem fim. O entrecruzamento das várias facetas identitárias 
dos sujeitos demandam formas de se pensar a interseccionalidade a partir de encontros fluídos e instáveis. Como afirmado por G. Valentine (2007), a compreensão da interseccionalidade como uma realização reconhece que as pessoas são ativas nos processos de produção de suas vidas, fugindo dos esquemas binários relacionados a opressores e oprimidos.

Por outro lado, estas intersecções foram pensadas pelas ciências sociais, via de regra, como se estivessem em um vácuo, sendo desconsideradas suas espacialidades. Quando as pesquisas geográficas têm olhares em relação às interseccionalidades, devido a motivos de recursos financeiros, tempo destinado à pesquisa, as várias narrativas levantadas em trabalhos de campo são aparadas, privilegiando-se algumas facetas identitárias em detrimento de outras.

Se a palavra-chave para esta discussão refere-se à complexidade das conexões entre dimensões de distintas categorias identitárias, isso se relaciona a proposição de McCall (2005) em 'The Complexity of Intersectionality'. Para ela, desde que os primeiros críticos alegaram que o feminismo reivindicava uma fala universal para todas as mulheres, as pesquisadoras feministas têm tomado a consciência das limitações do gênero enquanto uma única categoria analítica. Estas pesquisadoras têm alegado que a interseccionalidade as relações entre múltiplas categorias identitárias de sujeito - é uma categoria central em suas pesquisas.

Nesta direção, a autora aponta que a interseccionalidade é uma das contribuições mais importantes do feminismo acadêmico para as ciências sociais como um todo. Ao mesmo tempo, este novo paradigma, como denominado pela autora, traz consigo um problema metodológico, a forma como analisar várias trajetórias identitárias, que a partir de uma interseccionalidade, coexistem simultaneamente. Assim, fugindo do amplo leque de possibilidades propostas por vários caminhos de pesquisa, McCall evidencia três direções metodológicas para se trabalhar em interseccionalidade, na sua relação às categorias, ou seja, como se visualiza o entendimento analítico de categorias identitárias para se trabalhar com complexidades interseccionais na vida social. Estas possibilidades se referem à anticategorical complexity, intercategorical complexity e intracategorical complexity.

Inicialmente, a anticategorical complexity se baseia em metodologias que desconstroem categorias analíticas. Segundo McCall (2005), a vida social é irredutível, demasiadamente complexa, fluída e forjada a partir de múltiplas determinações para se pensar em categorias fixas. O caminho seria pensar as ficções sociais que produziriam desigualdades nos processos de produção de diferenças identitárias ${ }^{9}$. Em seguida, a intercategorical complexity refere-se à demanda dos pesquisadores na adoção, de forma provisória, de categorias analíticas existentes, com o objetivo de capturar as desigualdades entre os grupos sociais, alterando as múltiplas e contraditórias configurações de desigualdade ao longo da caminhada da pesquisa. Esta perspectiva refere-se ao trabalho com multigrupos. Finalmente, a intracategorical complexity coloca-se enquanto uma possibilidade intermediaria em um continuun entre a primeira e a segunda metodologia.

Assim como a primeira abordagem, que interroga os limites das definições e a segunda que reconhece as categorias como estáveis, mesmo que sejam representações sociais e se tenha uma postura crítica em relação às categorias, esta última é chamada de intracategorical porque os pesquisadores que trabalham neste sentido concentram-se em específicos grupos sociais, onde as intersecções que constituem as pessoas atravessam fronteiras de grupos tradicionalmente constituídos, revelando complexidades de experiências que são vividas dentro destes grupos, e como nesta discussão, através do grupo de travestis.

As pesquisas que trabalham com esta última possibilidade, segundo McCall, admitem o fato de que mesmo que se considerem as categorias como construções sociais, torna-se impossível fugir por completo do processo de categorização identitária do mundo. A direção tomada é a de desafiar as categorias, levantando a possibilidade da definição de novos grupos sociais, como o grupo das travestis, tanto novos em seu processo de nomeação, como também no sentido de ser uma construção intelectual.

O que mostra-se é que novos indivíduos são somados a agenda de pesquisa, grupos estes que como defendido por Butler (2003) não correspondem a linearidade entre sexo, gênero, prática sexual e desejo. Portanto, a crítica não se coloca à categorização em si, mas se relaciona a generalização de categorias. O que se busca de fato é trabalhar com pontos de intersecção que até agora foram negligenciados. Segundo sua perspectiva metodológica, McCall (2005) estabelece que o principal sujeito pesquisado em um processo de pesquisa, que tem por caminho pensar a identidade a partir da interseccionalidade, é qualquer grupo negligenciado. Isso se coloca como uma afirmação de grande importância, tendo visto a pequena produção geográfica brasileira, no tocante a vários grupos sociais, estando dentre eles as existências travestis. Assim, utilizando-se de narrativas dos sujeitos entrevistados, extrapolamos sua constituição ao grupo social mais amplo que é incorporada pelas travestis. 
Como visto em todas as falas das travestis que cederam suas histórias de vida, as travestis compartilham características de seu grupo, como dimensões de categorias identitárias que definem sua posição social enquanto grupo.

Portanto, a intersecção de identidades para o grupo de travestis envolvido com a atividade da prostituição no Sul do Brasil resulta de várias articulações de uma única dimensão de cada categoria, como gênero, sexualidade, cor da pele e grupo de renda. O que é múltiplo não se relaciona à interconexão de diferentes categorias, mas segundo a conexão entre diferentes dimensões de categorias de existência travesti. Estas interconexões entre diferentes dimensões de categorias não ocorre no vácuo, mas são constituídas por espacialidades, assim como as espacialidades constituem interseccionalidades, havendo uma cristalização temporária de relações sociais, particulares ao grupo de travestis, em distintas espacialidades e temporalidades.

Portanto, como analisado por McCall (2005), a questão não se coloca em negar a importância das categorias identitárias, mas salientar as formas como elas são produzidas, reproduzidas e experienciadas, e a partir do nosso olhar, através das espacialidades que são constituintes de todas as fases da vida das travestis. Este caminho aponta para a necessidade da compreensão do estabelecimento de identidades em seu fazer, dimensões de categorias identitárias que são valorizadas em determinadas espacialidades e desvalorizadas em outras.

Estas espacialidades não se colocam como meros receptáculos de ocorrências de interseccionalidades identitárias, mas operam-se processos de co-constuição mútua. Refletir sobre a relação entre espacialidades, interseccionalidades e sujeitos travestis demanda a compreensão de que estas relações têm seus conteúdos alterados a partir da escala geográfica que tomemos por referencial. É nesta perspectiva que podemos construir um diálogo entre as discussões relacionadas ao espaço. Utilizamos neste momento das proposições de Santos (1978) não como um discurso de autoridade, mas segundo a validade das suas proposições para a presente discussão. Na sua busca de construir um conceito de espaço, Santos nos apresenta que cada disciplina teria seu objeto estabelecido no conjunto dos sub-campos do conhecimento científico. Segundo ele, a Geografia teria como objeto de estudo a sociedade em sua dimensão espacial. Portanto, sua busca é definir um aspecto da realidade social a ser estudada, ou seja, o espaço. Para o autor, a Geografia visualiza o espaço como a natureza modificada pelo trabalho humano, onde a ideia de espaço natural cede lugar à ideia de natureza concebida, a construção permanente de uma natureza artificial, como sinônimo, espaço humano.

Compreendemos que o espaço é um fato social, constrangendo as ações de indivíduos e grupos sociais. Segundo Santos (1978), o espaço seria como as demais instâncias ou estruturas sociais, assim como a instância econômica, a político-jurídica e a ideológica. O espaço, enquanto quarta esfera de existência dos fenômenos seria uma estrutura social subordinada e subordinante, e mesmo estando inserido na lei da totalidade, possuiria certa autonomia.

Por outro caminho, especificamente refletindo sobre o espaço urbano, Corrêa (2003) afirma que este é reflexo e condição da sociedade. A partir da escala urbana, analisando a relação entre esta espacialidade e a vivência travesti, esta possibilidade geográfica se coloca como reflexo e condição do que é a sociedade. Sendo a sociedade desigual, o espaço apresenta-se como desigualmente organizado, mas simultaneamente condição à reprodução das mesmas relações de desigualdade. Lemos esta condição não a partir de um determinismo espacial, mas sim na possibilidade de evidenciar as espacialidades como compositoras de constrangimentos de escolhas sociais.

A partir da consideração realizada por Butler (2003) que o ocidente é estruturado a partir da linearidade entre sexo, gênero e desejo, as espacialidades ocidentais estruturam-se no que $G$. Valentine (1993) denomina como 'espaço heterossexual', ou seja, constrangendo as ações dos sujeitos em direção a esta configuração de práticas de gênero e sexualidade. Como apontado pela autora, a heterossexualidade é uma prática sexual dominante na cultura ocidental moderna, não definida apenas pelos atos sexuais nas espacialidades privadas, mas estabelecida a partir de relações de poder que se operam em todas as espacialidades cotidianas, espacialidades heterossexuais que se colocam enquanto invisíveis, até que suas fronteiras sejam transgredidas.

Evidenciamos que esta transgressão de fronteiras relaciona-se à vivência espacial, nas mais variadas possibilidades existenciais do grupo de travestis ao longo de suas vidas. A partir do pressuposto que todas as espacialidades são constituídas a partir de relações sociais, as mais variadas, esta nova complexidade apresenta-se como constituída por inter-relações, esfera da multiplicidade e sempre em construção (MASSEY, 2008).

Este caminho de reflexão evidencia o fato de que, como defendido por Massey (2008), os grupos sociais desenvolvem modos de incorporação de espacialidades as suas visões sociais de mundo, produzindo estratégias de gestão dos desafios espaciais que 
constrangem as ações dos sujeitos. Como levantado nos discursos das travestis, estas ações dialogam com a imposição do espaço ser reflexo e condição das formas de organização social hegemônicas.

Pensando estes processos a partir de sujeitos ativos, estas ações, tanto produzidas como envolvidas pelas práticas sociais, estabelecem um diálogo entre negociações cotidianas e constrangimentos hegemônicos gerais, apontando para o fato de que as interconexões entre diferentes dimensões de categorias identitárias dos sujeitos, ou melhor, os diversos arranjos interseccionais identitários são produzidos por escolhas conscientes, através das espacialidades, ou em relação às espacialidades, em processos de coconstituição mútua entre espacialidades e interseccionalidades.

Compreender o espaço como resultado de interrelações, esfera da multiplicidade e sempre em construção alinha-se a proposta acima relacionada às estratégias de gestão de desafios espaciais frente à imposição do espaço ser reflexo e condição das formas de organização socioespacial hegemônicas, pois como evidenciado por Massey (2008), esta forma de pensar o espaço pode contribuir na reflexão deste enquanto a esfera da política, ou seja, uma abertura para uma autêntica dimensão do político, ou uma conexão entre uma imaginação do espacial e do político.

Pensar a relação entre espacialidades e multiplicidades pressupõe o reconhecimento da coexistência simultânea da diferença, com próprias estórias e trajetórias, o que não quer dizer que estejam desconectadas de organizações sociais hegemônicas. Retornando novamente a proposição anterior, de que os diversos arranjos interseccionais identitários são produzidos por escolhas conscientes, através / em relação às espacialidades, isto demanda a aceitação de que não apenas a história, mas o espaço é aberto, pois segundo Massey, nesta possibilidade de espacialidade aberta interacional, sempre existem conexões por serem feitas, mesmo que em potencial. Portanto, o espaço é resultado de relações, demandando multiplicidade, não relações em sistemas coerentes e fechados, como se tudo se relacionasse a tudo. Não é uma simultaneidade completa ou um recipiente para identidades finais, "é um espaço de resultados imprevisíveis e de ligações ausentes" (MASSEY, 2008, p. 32).

Os processos de vinculação grupal das travestis relacionam-se às espacialidades através as quais são estabelecidas. Espacialidades e experiências identitárias interseccionais travestis são coconstituintes, performativamente relacionadas tanto à reprodução da heteronormatividade compulsória, como à transgressão destas mesmas normas. Desta forma, construímos em seguida uma análise das espacialidades constituidoras das memórias das travestis, produzindo elementos que são convertidos em elementos de identidade, através de processos de vinculação sócio-espacial.

\section{Entre Espaços Interditos e Espacialidades Relacionadas a Prostituição}

Como tratado por Massey, Allen e Sarre (1999), o conceito de espaço é central na organização da Geografia, conceito este que de tempos em tempos retornamos com boas razões. Este conceito é importante devido ao fato de que é tanto crucial na construção de nossos quadros de compreensão do mundo quanto como referenciais de orientação através dele. Os autores apontam que as ciências sociais como um todo tem reconhecido cada vez mais a importância do espaço, sendo este fenômeno denominado como 'spatial turn'.

Mesmo que tomemos como referência de reflexão um conjunto de discursos relacionados a todas as fases das vidas das travestis, através das mais variadas espacialidades, salientamos que estas espacialidades são / estão em processos permanentes de constituição. Tanto no hoje, quando estas espacialidades são vivenciadas nas memórias das travestis a partir das espacialidades vividas atualmente, quanto no momento da vivência específica no passado, as relacionalidades que constituíam estas espacialidades fazia-se a partir, como visto por Massey, Allen e Sarre (1999) no tocante a discussão sobre o conceito de espaço, de processos de se praticar e realizar estas espacialidades, pois segundo os autores, todos nós estamos embebidos nestes fazeres e práticas.

Evidenciamos que as memórias espaciais que foram resgatadas pelas travestis através do processo de pesquisa são elementos que constituem identidades interseccionais enquanto grupo de travesti, pois como proposto por Pollak (1992), a memória coloca-se enquanto um fator de extrema importância para o sentimento de continuidade e coerência de grupos sociais. As memórias que foram resgatadas pelo grupo focal são elementos de afirmação grupal. Mesmo que estas memórias não sejam idênticas a todas as travestis, os elementos que se colocam como comuns são elementos de identificação, através do cruzamento de experiências passadas, que são socializadas através dos territórios da prostituição travesti. Assim, vejamos abaixo as princuipais características do grupo focal objetivado nesta diuscussão ${ }^{10}$ : 
Espaços Interditos e a Constituição das Identidades

Travestis através da Prostituição no Sul do Brasil

\begin{tabular}{|c|c|c|c|c|c|c|}
\hline Nome & Idade & $\begin{array}{l}\text { Cidade de } \\
\text { Nascimento }\end{array}$ & Atividade & $\begin{array}{c}\text { Idade Saida } \\
\text { de Casa }\end{array}$ & $\begin{array}{l}\text { Idade de } \\
\text { Inicio da } \\
\text { Batalha }\end{array}$ & $\begin{array}{c}\text { Cidade que } \\
\text { mora } \\
\text { Atualmente }\end{array}$ \\
\hline Hera & 41 anos & $\begin{array}{c}\text { Porto Alegre } \\
\text { - RS }\end{array}$ & $\begin{array}{l}\text { Profissional } \\
\text { do sexo }\end{array}$ & 19 anos & 25 anos & $\begin{array}{l}\text { Balneário } \\
\text { Camboriú - } \\
\text { SC }\end{array}$ \\
\hline Atena & 35 anos & $\begin{array}{c}\text { Três Rios - } \\
\text { RJ }\end{array}$ & Cafetina & 19 anos & 19 anos & $\begin{array}{l}\text { Balneário } \\
\text { Camboriú - } \\
\text { SC }\end{array}$ \\
\hline Reia & 18 anos & $\begin{array}{c}\text { Campo } \\
\text { Mourão-PR }\end{array}$ & $\begin{array}{l}\text { Profissional } \\
\text { do Sexo }\end{array}$ & $\begin{array}{c}\text { Mora com a } \\
\text { mảe }\end{array}$ & 15 anos & Maringá - PR \\
\hline Demeter & 22 anos & $\begin{array}{c}\text { Ponta } \\
\text { Grossa-PR }\end{array}$ & $\begin{array}{l}\text { Profissional } \\
\text { do Sexo }\end{array}$ & 14 anos & 14 anos & Curitiba - PR \\
\hline Hestia & 46 anos & Niterói - RJ & $\begin{array}{l}\text { Profissional } \\
\text { do Sexo }\end{array}$ & 16 anos & 16 anos & Curitiba - PR \\
\hline Leto & 28 anos & Curitiba - PR & $\begin{array}{l}\text { Profissional } \\
\text { do Sexo }\end{array}$ & 16 anos & 19 anos & Curitiba - PR \\
\hline Artemis & 21 anos & $\begin{array}{c}\text { São José } \\
\text { dos Pinhais - } \\
\text { PR }\end{array}$ & $\begin{array}{l}\text { Profissional } \\
\text { do Sexo }\end{array}$ & $\begin{array}{c}\text { Mora com o } \\
\text { avô e tia }\end{array}$ & 20 anos & Curitiba - PR \\
\hline Afrodite & 38 anos & $\begin{array}{l}\text { Canoinhas - } \\
\text { SC }\end{array}$ & Cafetina & 13 anos & 16 anos & Curitiba - PR \\
\hline Circe & 28 anos & $\begin{array}{c}\text { Passo Fundo } \\
\text { - RS }\end{array}$ & $\begin{array}{l}\text { Profissional } \\
\text { do Sexo }\end{array}$ & 14 anos & 14 anos & Curitiba - PR \\
\hline Hécate & 29 anos & Guaiba - RS & $\begin{array}{l}\text { Profissional } \\
\text { do Sexo }\end{array}$ & 12 anos & 12 anos & $\begin{array}{c}\text { Florianópolis } \\
\text { - SC }\end{array}$ \\
\hline Dikè & 30 anos & $\begin{array}{c}\text { Florianópolis } \\
\text { - SC }\end{array}$ & $\begin{array}{l}\text { Profissional } \\
\text { do Sexo }\end{array}$ & 16 anos & 16 anos & $\begin{array}{c}\text { Florianópolis } \\
\text { - SC }\end{array}$ \\
\hline Tétis & 33 anos & $\begin{array}{c}\text { Florianópolis } \\
\text { - SC }\end{array}$ & Cafetina & 16 anos & 16 anos & $\begin{array}{c}\text { Florianópolis } \\
- \text { SC }\end{array}$ \\
\hline Dione & 46 anos & $\begin{array}{c}\text { Londrina- } \\
\text { PR }\end{array}$ & $\begin{array}{l}\text { Profissional } \\
\text { do Sexo }\end{array}$ & 17 anos & 17 anos & $\begin{array}{l}\text { Londrina - } \\
\text { PR }\end{array}$ \\
\hline Erinia & 38 anos & $\begin{array}{c}\text { Cachoeira do } \\
\text { Sul - RS }\end{array}$ & $\begin{array}{c}\text { Profissional } \\
\text { do Sexo }\end{array}$ & 11 anos & 12 anos & $\begin{array}{c}\text { Ponta } \\
\text { Grossa - PR }\end{array}$ \\
\hline Iris & 46 anos & $\begin{array}{c}\text { Ponta } \\
\text { Grossa - PR }\end{array}$ & $\begin{array}{l}\text { Profissional } \\
\text { do Sexo }\end{array}$ & $\begin{array}{c}\text { Mora com a } \\
\text { māe }\end{array}$ & 15 anos & $\begin{array}{c}\text { Ponta } \\
\text { Grossa - PR }\end{array}$ \\
\hline Hipólita & 28 anos & $\begin{array}{c}\text { Ponta } \\
\text { Grossa - PR }\end{array}$ & $\begin{array}{l}\text { Profissional } \\
\text { do Sexo }\end{array}$ & $\begin{array}{c}\text { Mora com a } \\
\text { mãe }\end{array}$ & 18 anos & $\begin{array}{c}\text { Ponta } \\
\text { Grossa - PR }\end{array}$ \\
\hline Pitia & 40 anos & $\begin{array}{c}\text { São } \\
\text { Raimundo } \\
\text { Nonato - PI }\end{array}$ & $\begin{array}{l}\text { Profissional } \\
\text { do Sexo }\end{array}$ & 9 anos & 18 anos & $\begin{array}{c}\text { Porto Alegre } \\
\text { - RS }\end{array}$ \\
\hline Eos & 24 anos & $\begin{array}{c}\text { Sapiranga - } \\
\text { RS }\end{array}$ & $\begin{array}{l}\text { Profissional } \\
\text { do Sexo }\end{array}$ & 16 anos & 18 anos & $\begin{array}{l}\text { Sapiranga - } \\
\text { RS }\end{array}$ \\
\hline Selene & 38 anos & $\begin{array}{c}\text { Herval Seco } \\
\text { - RS }\end{array}$ & $\begin{array}{l}\text { Profissional } \\
\text { do Sexo }\end{array}$ & 16 anos & 19 anos & $\begin{array}{l}\text { Sapiranga - } \\
\text { RS }\end{array}$ \\
\hline Febe & 38 anos & $\begin{array}{c}\text { Porto Alegre } \\
\text { - RS }\end{array}$ & $\begin{array}{c}\text { Profissional } \\
\text { do Sexo }\end{array}$ & $\ldots{ }^{12}$ & ...... & $\begin{array}{l}\text { Madri - } \\
\text { Espanha }\end{array}$ \\
\hline Estige & 26 anos & $\begin{array}{l}\text { São Luiz - } \\
\text { MA }\end{array}$ & $\begin{array}{l}\text { Profissional } \\
\text { do Sexo }\end{array}$ & 12 anos & $\ldots$ & $\begin{array}{l}\text { Madri - } \\
\text { Espanha }\end{array}$ \\
\hline Nèmesis & 33 anos & $\begin{array}{c}\text { Interior do } \\
\text { Ceará }\end{array}$ & $\begin{array}{l}\text { Profissional } \\
\text { do Sexo }\end{array}$ & ....... & ....... & $\begin{array}{l}\text { Madri - } \\
\text { Espanha }\end{array}$ \\
\hline
\end{tabular}

Quadro 1 - Características Gerais do Grupo Focal. 
Para esta discussão algumas características que consideramos relevantes na caracterização do grupo das travestis são destacadas. Inicialmente, podemos detectar que do total do grupo investigado, $45.5 \%$ das travestis possui idade entre 18 e 30 anos, $36.4 \%$ idade entre 33 e 40 anos, sendo que apenas $18.1 \%$ possui idade entre 41 e 46 anos. O fato das travestis serem relativamente jovens relaciona-se a circunstâncias de que, além da aquisição de doenças respiratórias advindas da contração da Aids, e doenças sexualmente transmissíveis, em geral, suas vidas são marcadas por muita violência, que via de regra culmina em uma morte precoce, tanto a sua morte como a morte das companheiras de batalha. Como visto em Cabral, Ornat e Silva (2011), a morte para o grupo de travestis não é algo que é experienciado a partir de longe, de tempos em tempos segundo o próprio ciclo da vida, mas faz parte de suas vidas cotidianas, caminhando a morte ao lado delas.

O sentido da vida para o grupo das travestis que foram o grupo focal desta reflexão, perante todos os riscos que estruturam suas vidas cotidianas, produz um sentimento de necessidade da vida presente e da existência de poucos planos futuros, não fazendo parte deste grupo a expectativa do envelhecimento e o cuidado de si para o dia de amanhã. $O$ grupo de travestis dialoga com um destino previsível de morte, uma interdição à vida, buscando extrair tudo que a vida pode proporcionar no hoje. Tendo uma vida marcada pela exclusão e a violência, é segundo o estabelecimento de pequenas brechas que elas conseguem estabelecer táticas de sobrevivência.

Outras informações evidenciadas nas entrevistas, que desmitificam a ideia da escolha 'livre' das travestis pela prostituição, referem-se ao fato de que apenas $18.1 \%$ das travestis entrevistadas vivem com suas famílias, sendo que a grande maioria delas (59\%) saiu de casa com idades que variam entre os 9 e $16 \operatorname{anos}^{13}$. Estes dados complementam-se à média de tempo de atividade de prostituição travesti que é de 16,3 anos $^{14}$.

$\mathrm{O}$ ocidente não reserva às travestis outra atividade socialmente 'bem afamada', a não ser a prostituição. Nossa proposta não é apregoar uma espécie de determinismo social, afirmando que o 'destino' de toda travesti é a prostituição, como já salientado por Peres (2005) no tocante a outras travestis que sobrevivem de outras atividades econômicas. $\mathrm{O}$ que a nossa convivência com o grupo focal levanta é a existência de um forte constrangimento social estruturado em um pequeno range de possibilidades, estando dentre elas a prostituição.

Mesmo que Benedetti (2000) argumente sobre a necessidade da separação entre travestis e prostituição, é fato que a grande maioria das travestis brasileiras encontra na prostituição uma das únicas possibilidades de sobrevivência. Mesmo que as territorialidades da prostituição estejam relacionadas a outras esferas existenciais do sujeito, não se pode minimizar que esta condição é, de certa forma, 'imposta' temporalmente e espacialmente as travestis, sobremaneira através da interdição às espacialidades do trabalho não relacionadas à prostituição.

Estes números e percentuais são fundamentais para o objetivo de captar as principais características do grupo focal escolhido. Todavia, estão longe de fornecer indícios completos da compreensão das dinâmicas identitárias interseccionais que dão coesão ao grupo, através de suas várias vivências espaciais. Devido a isto, mergulhamos nas experiências espaciais vividas pelas travestis que retiram seu sustento da atividade da prostituição através do Sul do Brasil.

Do total de evocações detectadas a partir de todas as entrevistas que foram realizadas, as principais espacialidades que são vivenciadas pelas travestis em todas as fazes da vida, referem-se a cidade, a casa, a pensão para travestis, a escola, outros países, a vizinhança, além dos maiores percentuais relacionados aos territórios intra-urbanos e ao território descontinuo da prostituição travesti. Da mesma forma, agrupamos na mesma categoria - 'Demais Espacialidades' - os percentuais menores que $1 \%$ de evocaçã ${ }^{23}$, como visto no gráfico abaixo.

O processo de conhecimento dos grupos sociais relaciona-se a sequências de fixações espaciais que proporcionam estabilidade aos sujeitos. Portanto, quanto mais marcantes são estas espacialidades, mais concretas serão as lembranças e memórias espaciais dos grupos sociais. Não temos por objetivo construir uma hierarquia das espacialidades que são ou foram vivenciadas pelas travestis, mas salientar a importância de cada espacialidade que foi resgatada na memória, através do processo de pesquisa.

Visualizamos a relação entre tempo, memória e espacialidades, como proposto por Harvey (2002, p. 200), pois se a proposição de que as temporalidades não são apropriadas pelos sujeitos e grupos sociais enquanto fluxos, mas como lembranças de espacialidades, "a história deve ceder lugar à poesia, $\mathrm{o}$ tempo ao espaço, como material fundamental da expressão social. Assim, a imagem espacial afirma um importante poder sobre a história". Como visto nas evocações relacionadas ao grupo focal, a espacialidade da casa aparece como o início do processo, na sua relação com a escola e a vizinhança. Um local como visto por Harvey (2002), estruturado a partir de pensamentos, sonhos e lembranças.

$\mathrm{Na}$ sua discussão com Bachelard (1964), Harvey 
Gráfico 1.

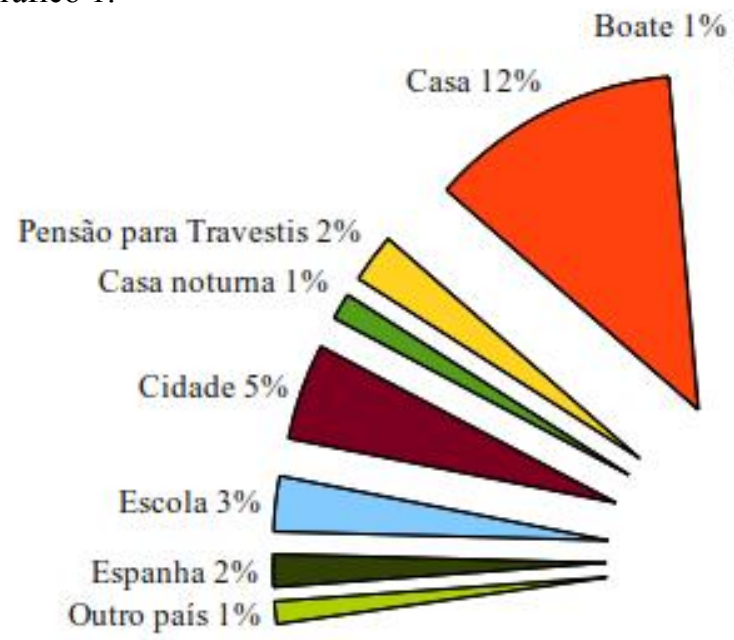

Território Intra-Urbano $22 \%$

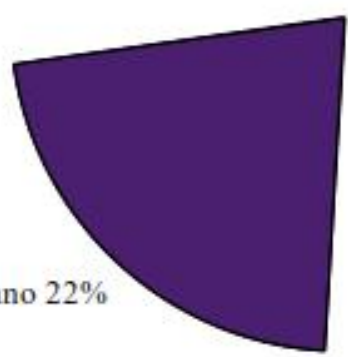

(2002) aponta que o espaço é constituído pelo tempo. Neste caminho, uma espacialidade que é de fundamental importância a constituição da memória é a casa, uma espacialidade estruturada a partir da proteção e do aconchego, o local de vivência dos seus protetores. Isto evidencia-se nos principais percentuais relacionados a casa, sendo que do total, 53\% referemse a relações familiares, $4 \%$ e $6 \%$ a relações paternas e maternas, respectivamente, $7 \%$ relacionado a prostituição e $15 \%$ relacionado-se ao sentimento de diferença ${ }^{16}$.

No tocante as categorias que tratavam das relações familiares, o levantando em campo demonstra que a casa não é o local da morada dos protetores das travestis, como proposto por Harvey (2002), proporcionando aconchego e proteção, mas sim estabelecida a partir de relações conflituosas. Os eixos de elementos nascidos deste agrupamento espacial referem-se inicialmente a expulsão de casa, sendo esta espacialidade interditada a travesti, na fase da infância. $\mathrm{O}$ elemento encontrado em quase todas as falas tratava da saída de casa enquanto menores, não enquanto uma escolha, mas enquanto uma imposição familiar, imposição esta mais relacionada aos pais e padrastos que as mães.

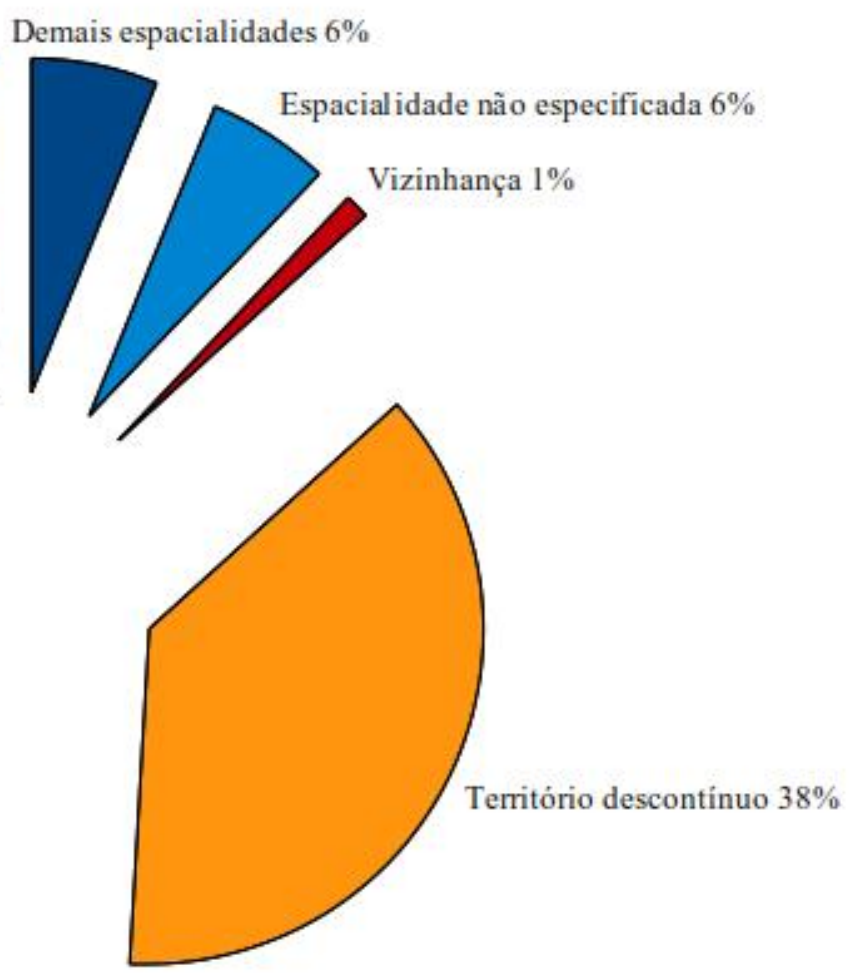

Configuração das Evocações por Espacialidade

Outros elementos levantados nas falas referem-se ao fato de que quando a aceitação existe na família, um dos caminhos desta acontece através da ajuda que a travesti realiza em casa. A vivência das travestis na casa, agora na vida adulta, é marcada por uma espécie de aquisição financeira do respeito, uma troca de bens materiais por aceitação familiar.

O elemento que evidenciamos é o fato de que se por um lado, existe a afirmação de que estas relações de interesse não ocorrem somente em grupos de travestis, esta possível troca é uma possibilidade de demonstração de um dos aspectos positivos da travesti à família, que é a bondade. Também se coloca como envolvida nessa dinâmica a aceitação através da independência financeira. Assim, o controle dos corpos e as interdições espaciais se fazem a partir da dependência econômica. Quando esta dependência não existe, o constrangimento de escolhas se mostra menor, ao lado de uma 'aceitação' maior. Além dos elementos acima elencados, a vida das travestis que são o grupo focal desta discussão estrutura-se a partir de paradoxos de aceitação e não aceitação, de interdição ou não interdição espacial. Como apontado nas falas, todas as travestis vivem dificuldades de aceitação através da casa, dificuldade esta também 
nascidas das relações maternas.

Especificamente nas relações maternas o que se evidencia é a sobreposição de preconceito e exclusão, aceitação e proteção. Nas relações paternas, o levantado a partir das falas das travestis refere-se ao preconceito, a violência e a expulsão de casa, pois $100 \%$ das falas a partir desta categoria estruturam-se segundo frases como: "quando eu falei pro теи pai eu levei uma tijolada17", "Até hoje meu pai não me aceita (...) ele conversa comigo por telefone, se eu for na casa dele ele não se sente bem, então eu prefiro nem ir ${ }^{18 ",}$ " "ele (pai) falou que se en queria ser gay, tu pode ser, a vida é tua, tu faz da tua vida o que tu quiseres, aí teve reticências, mas dentro da minha casa não! Muda de vida e aí tu continua morando aqui dentro 19 ", "eu sei que desde quando eu descobri quem eu realmente era, eu tava percebendo que теи pai não ia me aceitar, eu já cortei contato20", "o meu pai nunca ele pegou, ele nunca me aceitou, tanto que ele não aceitou nem os filhos, porque ele preferiu ficar com uma segunda mulher, do que aceitar os filhos ${ }^{21}$ ".

As frases acima transcritas referem-se ao sentimento de diferença que todas as travestis relembram a partir da espacialidade da casa e o sentimento de interdição espacial, tanto na relação com familiares, como especificamente com pais e mães. Mas além disso, apontam para o estranhamento de suas práticas de gênero frente a um mundo organizado de forma bipolar. Isto se refere ao que Butler (2008) denomina como corpos abjetos. Segundo a autora, a matriz excludente a partir da qual se formam os sujeitos demandam a produção simultânea tanto de seres abjetos quanto daqueles que são considerados socialmente como sujeitos, formando o campo exterior destes. Precisamente, a autora denomina 'abjeto' como as zonas invisíveis e inabitáveis da vida social, e ao nosso olhar, através das espacialidades inabitáveis e interditas, por pessoas que não usufruem os mesmos direitos, vivendo abaixo do sujeito.

As abjeções de alguns corpos e a sua correspondente não aceitação manifesta-se na vida cotidiana, e como neste momento de reflexão, a partir da espacialidade da casa. Como salientado por Butler, na sua entrevista a Prins e Meijer (1998), viver a partir de tais corpos é viver nas regiões sombrias da vida social. Nenhuma materialidade e espacialidade se apresentam acessíveis antes dos discursos, só existindo através dos discursos. Portanto, a partir das falas das travestis em relação a espacialidade da casa e ao sentimento de diferença, o que se evidencia em seus discursos é o fato de que este estranhamento ocorre desde a mais tenra idade. Este estranhamento acontece na relação com irmãos e irmãs, estranhamento este referente ao não se sentir bem usando roupas masculinas e não realizar brincadeiras masculinas, como o jogar bola, por exemplo. De forma complementar, suas brincadeiras referem-se ao universo feminino, como as brincadeiras de meninas.

A espacialidade da casa é constituída, via de regra, pela intersecção de dimensões de elementos identitários das travestis relacionadas ao gênero, faixa etária e sexualidade como preponderantes, fazendo parte desta mesma constituição os elementos relacionados ao grupo de renda. Todas as travestis entrevistas pertenciam, em sua maioria, às famílias que estavam contidas em grupos populares de baixa renda. Sendo esta dimensão identitária padrão a todas as travestis, a tensão ocorria em relação à dimensão identitária de gênero e sexualidade, tendo visto que a iniciação sexual de todas as travestis se fez, na média, através do período contido entre a infância e a adolescência. Sua existência espacial ocorria através da espacialidade da casa a partir de práticas de gênero e sexualidade que não correspondiam à linearidade entre sexo e gênero, prática sexual e desejo, culminando esta intersecção específica na sua saída de casa.

A transformação de sua posição nas relações de poder ocorre a partir da alteração da dimensão identitária relacionada à apropriação de obrigações da faze adulta. Se a partir da intersecção entre prática de gênero e sexualidades dissidentes e infânciaadolescência, o resultado era a interdição da casa, quando estas travestis tornam-se adultas ${ }^{22}$, outro elemento preponderante é adicionado a esta intersecção, ou seja, a capacidade de consumo, e seu potencial auxílio à família. Como visto nas falas, várias travestis têm sua posição nas relações de poder alteradas quando adquire uma capacidade de consumo, produzida pela prostituição, consumo este orientado ao auxílio familiar, resultando em uma nova configuração de relações familiares.

Segundo Massey (2008) as espacialidades estão em constante movimento, movimento este constituído por alterações nas inter-relações e diversidades que as constituem. Mas salientamos que, como visto pela autora, esta não é uma completa simultaneidade, mas sim constituída por imprevisíveis resultados e ausentes ligações. Quando da alteração da intersecção das dimensões entre distintas categorias identitárias do sujeito, passa-se da exclusão a aceitação, evidenciando-se uma nova configuração coconstituínte entre espacialidade da casa e interseccionalidade do sujeito travesti. Cabe salientar que quando as travestis saem de casa e adquirem um lar, permanente ou temporário, esta nova espacialidade será estruturada, não agora na relação com familiares, mas sim a partir da prática da 
prostituição na casa ${ }^{23}$.

Não podemos desconectar as espacialidades da casa das relações espaciais que acontecem a partir da espacialidade da escola, assim como da vizinhança, estruturadas a partir do controle do corpo exercido segundo pessoas externas à família. As características interseccionais da espacialidade da casa não se fazem desconectadas das vivências sociais possibilitadas através das espacialidades da escola e da vizinhança, a partir do grupo de travestis. Pensar a vivência travesti demanda refletir sobre o fato de que esta sexualidade dissidente, a homossexualidade, dialoga com a sexualidade tida como a normal, relacionada à heterossexualidade. Segundo G. Valentine (1993), o termo homossexualidade foi criado pela medicina no final do Séc. XIX. Sua apreensão relacionava-se a uma patologia, advinda de degeneração biológica, variando seu tratamento deste a castração até a psicanálise. Mesmo que atualmente a homossexualidade não seja tratada como tal, segundo a autora o estigma prevalece, tanto em espacialidades privadas quanto públicas.

De forma geral, a sexualidade é uma prática social relacionada especificamente a espacialidade do privado, ou seja, a casa. Contudo, como visto por G. Valentine, a heterossexualidade é institucionalizada a partir da lei, a partir de impostos, de sistemas de bemestar social, e festejada a partir de rituais públicos, como casamentos e batizados. Assim, é errôneo restringir a heterossexualidade apenas às espacialidades do privado, pois segundo a autora, a heterossexualidade é a prática sociosexual dominante na maioria das espacialidades cotidianas. Desta forma, as espacialidades da casa se conectam a espacialidades públicas, relacionadas a escola e a vizinhança.

Especificamente em relação à espacialidade da escola, Junckes e Silva (2009) apontam que esta espacialidade estrutura-se a partir de significados contraditórios. Para os autores, a partir de um conjunto de entrevistas realizadas com travestis, esta espacialidade fora rememorada como uma espacialidade marcada por sentimentos de exclusão, preconceito e sofrimento. As sexualidades, segundo os autores, também são componentes do espaço escolar, elementos estes que têm atualmente desestabilizado as práticas docentes que há tempo não eram dinamizadas por estas questões. A realidade relacionada ao nosso grupo focal em específico aponta para as mesmas direções, pois de $100 \%$ das evocações que tratavam da espacialidade da escolar, $74 \%$ se relacionaram a relações com o 'outro', apontando que a escolar é um local de constrangimentos e interdição para os corpos que não correspondem a heteronormatividade vigente, constrangimento este relacionado à indicação por professores que aquele corpo possui distúrbios hormonais e psicológico-psiquiátricos, e a exclusão e interdição por possuir comportamentos distintos ao estabelecido como masculinos. Outro elemento é que o preconceito vivenciado cotidianamente através do espaço escolar resulta no não desejo de continuar os estudos.

No tocante a $11 \%$ das evocações de tratavam do sentimento de diferença através do espaço escolar, o demonstrado é da não adequação ao comportamento dito masculino, e a existência de relacionamentos densos com meninas ao invés de meninos, pelo fato de possuir um comportamento padrão ao das meninas, tanto em relação ao comportamento corporal, quanto da não execução de atividades voltadas ao universo masculino relacionado aos esportes ${ }^{24}$.

Se o sentimento de diferença computa $11 \%$ das categorias relacionadas a espacialidade da escola, em relação à espacialidade da vizinhança, ela totaliza $68 \%$ deste total, ao lado da relação com amigos, relação com o outro, relação com a vizinhança e relação sexual, todos com $8 \%$. Especificamente em relação ao sentimento de diferença, as evocações apontam que as primeiras paixões ocorrem através da vizinhança, paixão esta estranhada por si e pelos pares sociais. Outro estranhamento se faz a partir das brincadeiras relacionadas a meninos e meninas e a intensidade de convivência com ambos, como discutido acima, em relação à espacialidade da casa. Entretanto, existem diferenciações no tocante a interseccionalidade identitária relacionada à espacialidade da vizinhança. O eixo interseccional variável refere-se a idade, assim como na espacialidade da casa. Outro eixo interseccional que ganha importância refere-se à descoberta e início da sexualidade a partir da vizinhança, pois quando estes dois eixos interseccionais alteram-se, o preconceito se amplia.

Como tratado por Mayol (1996), o bairro, ou mais especificamente em nossa problemática, a vizinhança, relaciona-se a uma "encenação da vida cotidiana (estabelecida a partir de) $)^{25}$ relações entre objetos, (...) o vínculo que une o espaço privado ao espaço público" (p. 38). Segundo o autor, é através da vida cotidiana, a partir da espacialidade da vizinhança, que se articulam duas dimensões fenomenais, primeiramente os comportamentos traduzidos em roupas, códigos de cortesia, e etc. Em segundo lugar, espacialidade composta, além dos comportamentos, pelos benefícios que as pessoas esperam obter por se comportar adequadamente nesta determinada espacialidade. Para o autor, a regulação que articula estes dois sistemas se refere a 'conveniência'. Como visto na afirmação do autor, a prática da vizinhança é desde a infância uma técnica do reconhecimento da 
posição de cada pessoa enquanto grupo, inscrevendose a vizinhança na história do sujeito. A espacialidade da vizinhança não é só apenas um local de conhecimento, mas de reconhecimento.

Contudo, como evidenciado nas falas das travestis, o reconhecimento realizado é segundo sua diferenciação em relação aos outros comportamentos das outras pessoas que fazem parte desta realidade e sua resultante interdição espacial. O que estas falas tratam dizem respeito ao fato de que este reconhecimento acontece segundo padrões de normalidade que são estabelecidos nestas espacialidades, diferenciando-se e estranhando-se as travestis destas normas de conveniência a partir da infância e adolescência. Este auto-reconhecimento da diferença relaciona-se a vivência espacial da vizinhança, através das brincadeiras de meninos e meninas, propiciando o ser reconhecido, e como analisado por Mayol, ser apontado com o dedo. Sendo o reconhecimento relacionado ao comportamento, isto salienta o corpo como o veículo de mensagens sociais e de controle.

Como segundo as espacialidades relacionadas a casa, a escola e a vizinhança, a espacialidade da cidade é um elemento componente da vivência cotidiana travesti. Esta espacialidade é estruturada, a partir da proposição de G. Valentine (1993), segundo o alinhamento da heterossexualidade como a sexualidade dominante. A heterossexualidade, a partir da interseccionalidade identitária entre sexo, gênero, prática sexual e desejo se expressa na organização da espacialidade da cidade, excluindo e interditando espacialmente pessoas e grupo social que não tem práticas cotidianas correspondentes a linearidade tida como a correta. O total de evocações que estavam relacionadas a esta espacialidade estavam orientados a relação com o outro (47 \%), ser travesti (13\%) e prostituição $(15 \%)^{26}$.

Inicialmente, as categorias referentes à relação com o outro apontam que é através da cidade que os corpos travestis são desejados. Todavia, este desejo anda ao lado do preconceito, a partir das roupas 'extravagantes' que algumas travestis dizem usar. Outros elementos evidenciados nas falas referem-se a imposição da aceitação e a indiferença para com o preconceito. Mesmo que as falas apontem um avanço no que diz respeito à diminuição da violência e ao aumento do respeito, a cidade é descrita pelas travestis que foram o grupo focal desta reflexão como uma espacialidade excludente e interdita. Esta exclusão é apontada no que se refere a própria vivência cotidiana, através do espaço urbano.

A espacialidade da cidade é construída segundo preconceito, tanto vivenciado na relação com outro, quanto aquele interiorizado a partir das vivências passadas. Como proposto por Mayol (1996), este vivenciar o espaço público inscreve-se em redes de sinais que são anteriores aos sujeitos. Assim, o andar de um corpo travesti pela cidade relaciona-se a um conjunto de convenções sociais que relacionam o sexo ao gênero e o gênero ao desejo, pois sair na rua é correr riscos, como salientado pelo autor.

A transgressão da conveniência relaciona-se a transgressão daqueles comportamentos que não convém, "mantém à distância, filtrando-os ou banindoos, os sinais de comportamentos ilegíveis (...), intoleráveis (...)" (MAYOL, 1996, p. 49). Esta conveniência relaciona-se a obrigatoriedade de se permanecer submisso as regras sociais, excluindo todo comportamento que não coaduna aos jogos 'normais' de comportamento social. Assim, o corpo travesti através da cidade coloca-se enquanto um corpo abjeto, vivendo estas pessoas, como disserta Butler (2008), em zonas inabitáveis que constituem e definem o terreno dos corpos 'normais'.

Por outro lado, a cidade excludente é evidenciada nas relações com o outro, a partir do acesso à habitação, apontando que as áreas segregadas estruturam-se para além de questões de não acesso à terra urbana segundo grupos de renda, mas também a partir de questões de gênero e sexualidade. Assim, um elemento evidenciado pelas travestis é o não acesso à habitação em programas habitacionais, a partir de relações de preconceito e do fato destas pessoas não possuírem ou pertencerem ao modelo hegemônico de família - pai / mãe / filho, todos heterossexuais.

As categorias relacionadas ao ser travesti colocamse como elementos em segundo lugar na intensidade de falas, quando tratadas da espacialidade da cidade. As falas evidenciam um continuun entre negação e complementação entre o ser travesti, apontando que ser travesti é apropriar-se de um conjunto de elemento do universo feminino, como roupas, adereços e comportamento, uma apropriação que é carregada enquanto uma marca nos corpos das travestis durante todo o tempo.

Quando as categorias tratavam da relação entre cidade e prostituição, elas evidenciam a separação entre áreas de prostituição, da mesma forma afirmando que do total de travestis que são conhecidas, quase $100 \%$ retiram seu sustento exclusivamente da atividade da prostituição. Esta ligação entre travesti e prostituição é evidenciada, segundo as falas das travestis, devido ao pequeno range de possibilidades de sobrevivência que existe para grupo. Outros elementos levantados nas evocações relacionam-se a exposição do corpo travesti através da relação entre cidade e prostituição, e o começo não intencional na 
prostituição, nascido do acaso através do caminhar pela cidade, atraindo o desejo dos homens.

Da mesma forma que em relação à cidade, as espacialidades relacionadas as casas noturnas constituem-se a partir de uma dimensão de exclusão, mas também segundo o paradoxo desta em relação a aceitação. Para as categorias que estiveram orientadas a espacialidade das casas noturnas, estas se estruturaram $100 \%$ a partir da mescla de elementos referentes a relação com o outro, prostituição e possibilidade de relacionamentos homoafetivos. No tocante a relação com o outro, as falas apontam boa recepção em espacialidades homoeróticas, alimentando o próprio desejo de transformação, mas também, quando estas espacialidades não estavam relacionadas ao homoerotismo, a interdição de acesso. Outra direção aponta que as casas noturnas são o começo para algumas travestis na vida da prostituição. E finalmente, quanto estas falas tratam da espacialidade das casas noturnas como uma possibilidade de relacionamentos homoafetivos, estas existem em potencial em casas noturnas LGBT. É a partir destas espacialidades que relacionamentos homoeróticos temporários podem acontecer.

As espacialidades que dizem respeito à pensão para travestis - também denominado pelo grupo como casas de cafetinas - e a Boate são compositoras de táticas de sobrevivência das travestis. Como visto no quadro 1 acima, é de 14,7 anos a média de idade em que as travestis ${ }^{27}$ saem de casa. O complemento desta informação quantitativa se relaciona a qualificação destas relações. Do total de evocações que foram produzidas através das entrevistas, as espacialidades relacionadas estas duas possibilidades alocam-se como duas estratégias de sobrevivência, frente a todos os processos de exclusão e interdição vivenciados pelas travestis ao longo de suas vidas.

Em relação à espacialidade relacionada à pensão para travestis, quando as categorias tratavam primeiramente das relações entre travestis (48 \%), estas estruturaram-se a partir das direções relacionadas a ausência de conflito na atualidade, a constituição da centralidade nas relações de poder, a partir da visualização da cafetina - ou chamada de proprietária da pensão - como a mãe das travestis, a existência e o controle de conflitos a partir da centralidade das cafetinas, a felicidade no reconhecimento do pertencimento junto ao grupo de travestis, a diminuição da existência de conflitos entre as travestis segundo o passado e atualmente, ao lado da solidariedade entre as travestis, mas também a responsabilidade das cafetinas em relação ao pagamento das despesas das casas. No tocante a relação com a cafetina ( 26 \%), as evocações trataram do benefício financeiro de possuir uma casa, uma pensão para as travestis, mas também a consciência de sua centralidade nas relações de poder. De forma paradoxal, o funcionamento de casas de cafetinas são estruturados a partir da exploração e segundo relações de violência. Todavia, existe o consenso de que a 'cafetinagem' é um mal necessário ao grupo. Para as evocações que trataram das relações com o outro (9 $\%$ ) e a prostituição $(9 \%)$, o que se evidencia é tanto uma busca pela prostituição quanto uma conexão entre a prostituição de rua e a prostituição por anúncios de jornais e através da internet. Da mesma forma, no tocante a relação com o outro, as falas estruturam-se a partir de péssimas condições de vida e de insalubridade. Finalmente, para as categorias referentes a relações familiares $(4 \%)$ e a apropriação de tecnologias de transformação do corpo das travestis (4\%), se em relação ao primeiro termo, o que temos é a existência de relações, através da espacialidade da casa de cafetina, segundo padrões familiares, com a obrigação dos afazeres domésticos relacionados àquelas que não 'trazem o dinheiro para casa', em relação ao segundo termo, aponta-se que algumas travestis, conhecendo o ofício da colocação de silicone nos corpos das travestis, possuiriam a prática de ensinar este ofício a uma travesti que seria a aprendiz desta atividade. Para a categoria prostituição, esta é uma possibilidade ligada em sua grande maioria a uma atividade de aluguel de quartos, a partir do pagamento diário.

Em relação à espacialidade da boate, a prostituição totaliza $86 \%^{28}$. As falas que tiveram esta direção foram estabelecidas a partir dos elementos relacionados ao cárcere privado, a diferença de comportamento dos clientes através do grupo de amigos, o início da prostituição em boates, a prostituição como escolha constrangida, a prostituição por contato entre boates localizadas em várias cidades, a transformação da prostituição, a prostituição travesti através das boates como glamour, e finalmente, a ampliação de possibilidades espaciais a partir de viagens pelo Brasil através da prostituição em boates.

A existência travesti, ao longo do desenrolar da vida, é atravessada por espaços interditos e por espacialidades relacionadas direta ou indiretamente à prostituição, como casas de cafetinas e as boates. O paradoxo de suas existências relaciona-se a processos de exclusão e de acolhida, a partir de formas contraditórias e complementares, pois se nas espacialidades relacionadas a casa, a vizinhança, a escola, a cidade $\mathrm{e}$ as casas noturnas, a interseccionalidade de diferentes dimensões de categorias identitárias da existência travestis pode ser desvalorizadas, culminando muitas vezes na 
interdição à estas espacialidades, por outro lado, de forma complementar, estas mesmas interseccionalidades podem ser valorizadas em outras espacialidades, como referente as pensões para travestis e as boates, pois as ações sociais de interdição espacial proporcionam, complementarmente, o fortalecimento de espacialidades e atividades relacionadas à prostituição. Assim, exclusão e inclusão não se colocam como oposicionais. Ao contrário, complementam-se compondo espacialidades travestis multidimensionais.

\section{Considerações Finais}

A presente discussão evidenciou a relação entre espacialidades interditas e a constituição de identidades através da prostituição travesti no Sul do Brasil. As experiências vividas através das espacialidades relacionadas a casa, a escola e a vizinhança, a cidade e as casas noturnas, a pensão para travestis e as boates apontam que as histórias de vida de cada travesti são socializadas intersubjetivamente, produzindo elementos identitários interseccionais das travestis que vivem da prostituição, produzidas por repetições de situações de interdição vividas em todas as fases da vida, processos estes de identificações temporalmente e espacialmente cambiantes e móveis.

As espacialidades que são vivenciadas pelas travestis que foram o grupo focal da presente discussão se constituem por paradoxos de heteronormatividade e transgressão. As vinculações grupais relacionam-se às espacialidades, assim como as espacialidades referemse a estas vinculações, co-constituídas mutuamente. Como visto por Pollak (1992), o substrato a priori de análise, na relação entre memória, identidade interseccional e espacialidade, refere-se ao fato de que a memória é um fenômeno individual e íntimo da pessoa. Mas, além disso, construído através dos grupos sociais, um fenômeno social, que é elaborado coletivamente, tanto relacionado aos fatos vividos pessoalmente, aqueles que são vividos indiretamente ou como nas palavras do autor, por tabela, quanto aqueles que são de certa forma herdados. Evidenciamos a existência dos três elementos que fazem parte da memória do grupo das travestis envolvidas com a atividade da prostituição no Sul do Brasil.

Primeiramente, todas as espacialidades acima tratadas foram vividas pelas travestis. Além disto, estes acontecimentos - quando socializados a partir das espacialidades de convívio como a pensão para travestis e as boates - passam a ser vividas 'por tabela' por todas as pessoas envolvidas nas trocas sociais cotidianas. Quando os acontecimentos que foram vividos tanto individualmente, quanto 'por tabela', juntam-se as vivências cotidianas, agora estabelecida através da espaço-temporalidade do grupo de travestis que sobrevivem da prostituição, ocorre "um fenômeno de projeção ou de identificação com determinado passado, tão forte que podemos falar numa memória quase que herdada" (POLLAK, 1992, p. 2).

Pensando que os fatos que foram resgatados pelas memórias colocam-se enquanto elementos identitários interseccionados, todas as três dimensões de memórias vividas pelo grupo constitui intersecções identitárias a partir de dimensões que se entrecruzam. As narrativas que foram levantadas individualmente a partir das entrevistas extrapolam a constituição do grupo mais amplo, que é apropriada por cada pessoa. Desta forma, a interseccionalidade produzida por estas relações refere-se ao cruzamento de experiências temporais e espaciais do grupo investigado. Estes espaços memorias relacionados a casa, a escola e a vizinhança, a cidade e as casas noturnas colocam-se, de forma geral, como espacialidades interditas a vivência travesti, interdições estas que são elementos da constituição das identidades travestis.

As intertextualidades relacionadas aos vários textos que compõe a vivência cotidiana travesti, ao longo de suas vidas, refere-se ao que Silva (2009b) denomina como 'produção do espaço interdito'. Assim, as espacialidades estruturam-se tanto a partir do que lhe é visível quanto daquilo que se coloca como invisível. O que as entrevistas evidenciam é que todas estas espacialidades se colocam, via de regra para o grupo focal, enquanto espacialidades interditas, se reproduzindo cotidianamente através das existências travestis, pois como proposto pela autora, "as travestis são culpabilizadas pela sua própria exclusão (...), e o espaço se institui como um dos elementos mais eficazes da construção das táticas polimorfas de poder, (...) que garantem a manutenção das normas compulsórias de gênero" (SILVA, 2009b, p. 149).

De forma paradoxal, são estas mesmas experiências temporais e espaciais que produzem um questionamento e uma desestabilização da organização binária do ocidente, a partir da heteronormatividade. As existências das travestis envolvidas com a atividade da prostituição no Sul do Brasil são atravessadas por espaços interditos e várias espacialidades relacionadas a prostituição, locais de exclusão e de acolhida, em processos contraditórios e complementares.

\footnotetext{
1 Esta discussão é parte da tese de doutorado intitulada 'Território Descontínuo e Multiterritorialidade na Prostituição Travesti através
} 
do Sul do Brasil' defendida no ano de 2011, no Programa de Pós-Graduação em Geografia Universidade Federal do Rio de Janeiro.

2 Pesquisador do Grupo de Estudos Territoriais - GETE / UEPG.

3 Entrevistas cedidas pela pesquisadora Joseli Maria Silva (Pós-Doutorado em Geografia e Gênero na Universidade Complutense de Madrid, 2008).

4 Outro exemplo de diagnóstico psiquiátrico pode ser visto em Freud (1938), em relação a Three Contributions to the Theory of Sex. Nesta discussão, tratando sobre o objeto sexual dos invertidos, ou como denominado por ele, como uma modalidade de inversão denominada de hermafroditismo psíquico, Freud propõe que "não há dúvida de que um maior número de invertidos masculinos têm conservado o caráter psíquico de virilidade, possuindo, portanto, poucas características secundárias do sexo oposto e buscando em seu objeto sexual características psíquicas propriamente femininas. Se não fosse assim, não se explicaria porque a prostituição masculina que se oferece aos invertidos trata - hoje como na antiguidade - de copiar as mulheres nos vestidos, aspectos exteriores e comportamentos, sem que esta imitação pareça ofender o ideal dos homossexuais masculinos" (FREUD, 1938, P. 560).

5 O volume de entrevistas computaram 14 horas e 43 minutos.

6 Buscando triangular as informações colhidas junto as travestis, fora realizado entrevistas com 7 Ongs que tem por objetivo estabelecer trabalhos orientados a prevenção de DST/HIV - Aids, e com conexões com grupos de travestis que vivem da prostituição. Estas Ongs estavam localizadas nos municípios de Curitiba - Paraná (2 Ongs), Florianópolis - SC (1 Ong), Joinville - SC (1 Ong), Ponta Grossa - PR (1 Ong), Porto Alegre - RS (1 Ong), Sapiranga - RS (1 Ong). Portanto, este volume de evocações também é composto pelas respostas de campo obtidas das Ongs.

7 Publicação original - HALL, S. The Question of Cultural Identity. In: HALL, S; HELD, D; McGREW, T. Modernity and its future. Cambridge: Politic Press, 1992.

8 Um maior aprofundamento sobre esta questão pode ser visto em Feyerabend (1977). Segundo o autor, os fenômenos não permitem, no momento da construção de um mundo conceitual, que nos prendamos a apenas um dado sistema epistemológico, pois fenômenos complexos, com elementos que possam ser imprevistos, reclamam procedimentos complexos.

9 Essas discussões podem ser vistas em Foucault em 'The Archaeology of Knowledge and the Discourse on Language' (1972) e Derrida em 'Of Grammatology '(1974).

10 Com o objetivo de proteger estas fontes, optamos em utilizar nomes que reportam as figuras femininas contidas na Mitologia Grega e Romana.

11 O termo 'batalha' refere-se, para o grupo de travestis, à atividade da prostituição.

12 Sem informações.

13 Em 9\% das entrevistas não fora possível identificar o período da vida em que saíram de casa.

14 Em 13,6 \% das entrevistas não fora possível levantar o ano de início na atividade da prostituição.

15 Espacialidades relacionadas a casa de passagem, o comércio, a delegacia, espaços diversos de sociabilidade, exército, instituições religiosas, médicas e militares, motel, Ongs, presídios, trabalho e universidades.

16 O restante das falas, que computaram percentual igual ou inferior a $2 \%$, estiveram orientadas a relação com padrastos, outros familiares, com companheiros, com o outro, com as espacialidades, auto imagem, transformação do corpo e ser travesti.

17 Entrevista realizada com Héstia, em Curitiba - PR, em 19 de maio de 2009.

18 Entrevista realizada com Afrodite, em Curitiba - PR, em 31 de julho de 2008.

19 Entrevista realizada com Hera, em Balneário Camboriú, em 26 de maio de 2009.

20 Entrevista realizada com Artemis, em Curitiba - PR, em 23 de junho de 2010.

21 Entrevista realizada com Erinia, em Ponta Grossa - PR, em 30 de julho de 2010. 
22 Não entendemos para o grupo focal da presente tese o termo 'adulta' em relação a idade acima de 18 anos, mas a apropriação de obrigações sociais relacionadas a esta idade, que se refere a responsabilidade da sobrevivência.

$23 \quad 7 \%$ das evocações relacionadas a espacialidade da casa trataram da prostituição.

24 O restante dos percentuais estavam relacionados ao sentimento de frustração, ser travesti, transformação do corpo e prostituição.

25 Não consta no original.

26 As demais direções de fala estava relacionadas a relação entre travestis, ao sentimento de diferença, a transformação do corpo, a auto-imagem, a percepção social e a relação com as espacialidades.

27 Esta média não computa 4 travestis que vivem com seus familiares e 2 que não fora possível obter esta informação.

28 O restante das evocações estiveram relacionadas a relação com o outro e sentimento de diferença.

\section{Referências}

ANDERSEN, Margaret; COLINS, Patrícia. Race, class and gender - An Anthology. Belmont, CA: Wadsworth, 1992.

BACHELARD, Gaston. The Poetics of Space. New York: Orion Press. 1964.

BARDIN, Laurence. Análise de conteúdo. Lisboa: Edições 70, 1977.

BENEDETTI, Marcos. Toda Feita: o corpo e o gênero das travestis. Porto Alegre, 2000. Dissertação (Mestrado em Antropologia Social) - Programa de Pós-Graduação em Antropologia Social, Universidade Federal do Rio Grande do Sul, Porto Alegre, 2000.

BROWNE, Kath. Genderism and the Bathroom Problem: (re)materialising sexed sites, (re)creating sexed bodies. Gender, Place and Culture , vol. 11, $\mathrm{n}^{\mathrm{o}}$ 3, p. 331 - 346, September 2004.

BROWNE, Kath; LIM, Jason. Trans lives in the 'gay capital of the UK' . Gender, Place and Culture , v.
17 , n. 5 , p. $615-633$, October 2010 .

BROWNE Kath; NASH, Catherine; HINES, Sally. Introduction: towards trans geographies . Gender, Place and Culture , v. 17, n. 5, p. 573 - 577, October 2010.

BUTLER, Judith. Problemas de Gênero: feminismo e subversão da identidade. Rio de Janeiro: Civilização Brasileira, 2003.

Deshacer el Género. Buenos Aires: Paidós, 2006.

. Cuerpos que Importan - Sobre los Límites Materiales y Discursivos del 'Sexo'. Buenos Aires: Paidós, 2008.

CABRAL, Vinicius; ORNAT, Marcio Jose; SILVA, Joseli Maria. Algumas Considerações sobre as Relações entre Espaço, Violência e a Vivência Travesti na Cidade de Ponta Grossa - Paraná . Geografia UFPI, v. 9, n. 31, p.1-17, março 2011.

CORRÊA, Roberto Lobato. Espaço, Um ConceitoChave da Geografia. In: CASTRO, Iná Elias de; GOMES, Paulo Cesar da Costa; CORRÊA, Roberto Lobato (Orgs.). Geografia: Conceitos e Temas. Rio de Janeiro: Bertrand Brasil, 1995, p. 15 - 47.

O Espaço Urbano. 4a Edição. São Paulo:

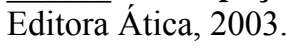

CRENSHAW , Kimberlé Williams. Mapping the Margins: Intersectionality, Identity Politics, and Violence Against Women of Color . In: FINEMAN, Martha; MYKITIUK, Rixanne. The Public Nature of Private Violence . New York: Routledge, 1994, p. 93 -118 .

DERRIDA, Jacques. Of Grammatology. Baltimore: Johns Hopkins University Press, 1974.

DOAN, Petra. Queers in the American City: Transgendered perceptions of urban space . Gender, Place and Culture , v. 14, n. 1, p. 57 - 74, February 2007 .

. The tyranny of gendered spaces - reflections from beyond the gender dichotomy . Gender, Place and Culture, v. 17, n. 5, p. 635 - 654, October 2010.

FEYERABEND, Paul. Contra o Método. Rio de Janeiro: Francisco Alves, 1977. 
FOUCAULT, Michel. The Archaeology of Knowledge and the Discourse on Language. New York: Pantheon Books, 1972.

FREUD, Sigmund. Three Contributions to the Theory of Sex. In: FREUD, Sigmund. The Basic Writings of Sigmund Freud. (Trad. Ed. Abraham Arden Brill). New York, The Modern Library, 1938.

HALL, Stuart. A identidade Cultural na PósModernidade. $8^{\mathrm{a}}$ Edição. Rio de Janeiro: DP\&A, 2003.

HARVEY, David. Condição pós-moderna. São Paulo: Edições Loyola, 2002.

HINES, Sally. Queerly situated? Exploring negotiations of trans queer subjectivities at work and within community spaces in the UK. Gender, Place and Culture, v. 17, n. 5, p. 597 - 613, October 2010.

JUNCKES, Ivan Jairo; SILVA, Joseli Maria. Espaço Escolar e Diversidade Sexual: Um Desafio às Políticas Educacionais no Brasil . Didácticas Específicas, n. 1, p. 148 - 166, 2009.

KNOPP, Larry. Ontologies of Place, Placelessness, and Movement: queer quests for identity and their impacts on contemporary geographic thought . Gender, Place and Culture , v. 11, n. 1, p. 121 - 134, March 2004 .

KOBAYASHI, Andrey; PEAKE, Linda. Unnatural discourse: 'Race' and gender in geography. Gender, Place and Culture, v. 1, p. 225 - 243, 1994.

KULICK, Don. Travesti. Prostituição, sexo, gênero e cultura no Brasil. Rio de Janeiro: Editora Fiocruz, 2008.

MASSEY, Dorren. Pelo Espaço - Uma Nova Política da Espacialidade. Rio de Janeiro: Bertrand Brasil, 2008.

MASSEY, Doreen; ALLEN, John; SARRE, Philip. Human Geography Today. Cambridge: Polity Press, 1999.

MAYOL, Pierre. O Bairro. In: CERTEAU, Michel de; GIARD, Luce; MAYOL, Pierre. A invenção do cotidiano: 2. Morar, Cozinhar. Petrópolis: Vozes, 1996 , p. $37-69$.
McCALL, Leslie. The Complexity of Intersectionality. Signs, v. 30, n. 3, p. $1771-1800$, 2005.

MONK, Janice; HANSON, Susan. On not excluding half of the human in human geography. The Professional Geographer, v. 34, p. 11 - 23, 1982.

NARVAZ, Martha Giudice; KOLLER, Sílvia Helena. Metodologias feministas e estudos de gênero: articulando pesquisa, clínica e política. Psicologia em Estudo, v. 11, n. 3, p. 647-654, set/dez 2006.

NASH, Catherine. Trans geographies, embodiment and experience . Gender, Place and Culture , v. 17, n. 5 , p. $579-595$, October 2010 .

PEAKE, Linda. 'Race' and sexuality: Challenging the patriarchal structuring of urban social space. Environment and Planning D: Society and Space, v. 11, p. $415-432,1993$.

PERES, Wiliam. Subjetividade das travestis brasileiras: da vulnerabilidade da estigmação à construção da cidadania. Rio de Janeiro, 2005. Tese (Doutorado em Medicina Social) - Programa de PósGraduação em Medicina Social, Universidade Estadual do Rio de Janeiro, Rio de Janeiro, 2005.

POLLAK, Michael. Memória e Identidade Social . Estudos Históricos, v. 5, n. 10, p. $200-212,1992$.

PRATT, Geraldine. Geographies of Identity and Difference: Marking Boundaries . In: MASSEY, Doreen; ALLEN, John; SARRE, Philip. Human Geography Today. Oxford: Polity Press, 1999, p. $151-167$.

Collaborating across our differences.

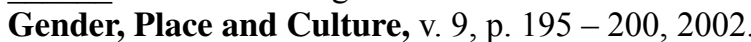

PRINS, Baukje; MEIJER, Irene Costera. How Bodies Come to Matter: An Interview with Judith Butler. Signs, v. 23, n. 2, p. $275-286,1998$.

ROOKE, Alison. Trans youth, science and art: creating (trans) gendered space . Gender, Place and Culture, v. 17, n. 5, p. 655 - 672, October 2010.

RUDDICK, Susan. Constructing difference in public spaces: Race, class, and gender as interlocking systems. Urban Geography, v. 17, p. 132 - 151, 1996. 
SANTOS, Milton. Por uma Geografia Nova. São Paulo, Hucitec, 1978.

SILVA, Joseli Maria. Geografia, Gênero e Sexualidades: A Experiência Travesti. In: III COLÓQUIO NACIONAL DO NÚCLEO DE ESTUDOS EM ESPAÇOS E REPRESENTAÇÕES NEER, Anais. Porto Velho, 1 a 6 de novembro 2009a, p. $1-36$.

A Cidade dos Corpos Transgressores da Heteronormatividade. In: SILVA, Joseli Maria (Org.) Geografias Subversivas - Discursos sobre Espaço, Gênero e Sexualidade. Ponta Grossa: Editora TodaPalavra, 2009b, p. 135 - 149.

VALENTINE, David. Imagining Transgender - an ethonography of a category. London: Duke University Press, 2007.

VALENTINE, Gill. (Hetero)Sexing Space: Lesbian Perceptions and Experiences of Everyday Spaces. Environment and Planning D: Society and Space, v. 11, p. $395-413,1993$.

Theorizing and Researching Intersectionality: A Challenge for Feminist Geography. The Professional Geographer, v. 59, n. 1, p. $10-21$, 2007.

WHITEHAND, Jeremy. The problem of anglophone squint. Area, v. 37, n. 2, p. $228-230,2005$.

WOMEN AND GEOGRAPHY STUDY GROUP (WGSG). Geography and gender: An introduction to feminist geography. London: Hutchinson, 1984. 